\title{
Genistein isoflavone and male fertility: The saga of genistein
}

\author{
Kumi-Diaka J* \\ Department of Biological Sciences, College of Science, Florida Atlantic University, USA
}

Reproductive function is dependent on the general homeostasis of the body and specifically on the health (physiology and function) of the hypothalamic-pituitary-gonadal axis. Among external factors that influence fertility in both genders in animals and humans, is nutrition (animals and plants origin), besides diseases.

Phytoestrogens are plant-derived chemicals that exhibit estrogenlike biological activities. Genistein isoflavone is the most abundant non-steroidal phytochemical in soy and soy products. Genistein is structurally related to estrogen; and like other phytochemicals, it binds to estrogen receptors 1 and 2 (ESR $1 \& 2$ ) and exhibits both estrogenic and anti-estrogenic activities [1]. Furthermore, genistein exhibits several pharmacological effects unrelated to its estrogenic properties, including: a) Inhibition of angiogenesis (formation of new blood vessels), inhibition of microsomal lipid peroxidation, inhibition of topoisomerase activity and tyrosine kinase signaling pathways and b) Regulation of both pro- and anti-apoptotic proteins [1]. Such multifunctional mechanistic potentials of genistein indicate the extend of genistein's varying effects on body organ systems.

Documented evidence indicates that most phytochemicals including genistein, influence reproductive physiology and function in both humans and animals and in both males and females [2]. However, the effect of genistein and other phytochemicals on male fertility has so far been unequivocal. Genistein may influence male fertility by directly targeting testicular function such as spermatogenesis (sperm cell production) and steroidogenesis (androgen/testosterone production) or indirectly influencing the endocrine activities of the hypothalamic-pituitary-testicular triangular axis (the production of GHRH-gonadotropin hormone releasing hormone, LH/ICSHluteinizing hormone/interstitial cell stimulating hormone, FSH-follicle stimulating hormone). Genistein is known to have direct effect on mature spermatozoa function. Data from previous studies alluded to the potential clinical significance of genistein in the treatment of testicular dysfunction [3]. Significant genistein-induced recovery and improvement in semen quality (morphology, motility, amount, capacitation- fertilizing capabilities) has been documented in cases of drug-induced testicular dysfunction in animal studies [1]. It is probable that the anti-oxidants in genistein could protect sperm cells from damage by free radicals from drugs, foods, and other deleterious materials.

In other studies, both human and animal sperm cells exposed to high concentrations of genistein exhibited some forms of infertility, manifested by abnormal spermatogenesis such as low sperm numbers, morphological abnormalities of the sperm cells, abnormal motility or lack of motility and loss of fertilizing capabilities (due to loss of sperm capacitation) [4]; https://www.fertilitytips.com/soy-and- infertility-is-there-a-link/. The overall implication here is genisteininduced infertility (decrease fertility). Inevitably, genistein being phytoestrogenic, could negatively impact the hormonal activities of the hypothalamic-pituitary-testicular axis and exert adverse effects on spermatogenesis and steroidogenesis on higher doses [5]. These agonistic and antagonistic activities and/or properties of genistein, partially account for both the positive/favorable and negative/ unfavorable effects of genistein on male fertility. This is also the scenario in females (genistein-induced infertility at very high concentration). Inevitably, the effect of genistein on male/female fertility will depend on the dose given. Lower doses of genistein seem to improve fertility and offer protection against insult on the reproductive system (the testes/ ovaries and the hypothalamic-pituitary- gonadal triangle); while higher doses appear to adversely affect fertility, manifested by poor semen quality (aestenoteratozoospermia) in the male.

Nutritionally, it is to be noted that the main source of genistein is soy beans and its products. Genetically-modified soy protein is found in a myriad of food products including dairy products, veggies, snack bars, breakfast specials and many others (check the fine prints on the labels). Major studies have yielded results that indicate that, the genetically modified soy protein inflicts serious havocs on the reproductive system in both genders, leading to varying forms of infertility, compared to organic soy or non-soy diet (https://www.fertilitytips.com/soy-andinfertility-is-there-a-link/). The effects of soy, and therefore of genistein, on fertility in both genders have so far been unequivocal. The available information so far, indicate the expected outcome of genistein exposure or soy product consumption, would be based on the dose (of genistein) and/or choice/type of soy product/protein diet (genetically modified or organic soy product). Soy-food products abound everywhere. Up-dodate information reveals both the good and bad sides of genistein cum soy products. The effects on fertility is so far unspecific/unequivocal and depend on multiple factors. However, with respect to the fight against cancers such as prostate cancer, the phytoterapeutic efficacy of genistein as adjunct therapy has been very significant.

\section{References}

1. Cyrus Jalili, Sharareh Ahmadi, Shiva Roshankhah, Mohammad Reza Salahshoor (2016) Effect of Genistein on reproductive parameter and serum nitric oxide levels in morphine-treated mice. Int J Reprod Biomed (Yazd) 14: 95-102.

${ }^{\star}$ Correspondence to: James Kumi-Diaka DVM MS PhD DSC (hon), Department of Biological Sciences, College of Science, Florida Atlantic University, USA, E-mail: jdiaka@fau.edu

Received: December 25, 2018; Accepted: January 16, 2019; Published: January 18,2019 
2. Sirotkin AV, Harrath AH (2014) Phytoestrogens and their effects. Eur J Pharmacol 741: $230-236$.

3. Martinez-Soto JC, de Dios Hour cade J, Gutiérrez-Adán A, Landeras JL, Gadea J (2010) Effect of genistein supplementation of thawing medium on characteristics of frozen human spermatozoa. Asian J Androl 12: 431- 441.
4. Opałka M, Ciereszko R (2004) Genistein affects testosterone secretion by Leydig cells in roosters (Gallus gallus domesticus) Reproduction 4: 185-193.

5. Cederroth CR, Auger J, Zimmermann C, Eustache F, Nef S. Soy (2010) phytooestrogens and male reproductive function: a review. Int $J$ Androl 33: 304-316.

Copyright: (C2019 Kumi-Diaka J. This is an open-access article distributed under the terms of the Creative Commons Attribution License, which permits unrestricted use, distribution, and reproduction in any medium, provided the original author and source are credited. 